\title{
Application of dexmedetomidine combined with sufentanil in colon cancer resection and its effect on immune and coagulation function of patients
}

\author{
LIQUN ZHAO ${ }^{1,2}$ and YINGLAN LI ${ }^{1}$ \\ ${ }^{1}$ Xiangya Nursing School, Central South University, Changsha, Hunan 410013; \\ ${ }^{2}$ Xiangya Hospital Central South University, Changsha, Hunan 410008, P.R. China
}

Received October 22, 2019; Accepted November 14, 2019

DOI: $10.3892 / \mathrm{ol} .2020 .11643$

\begin{abstract}
Application of dexmedetomidine combined with sufentanil in colon cancer resection and its effect on immune and coagulation function of patients was studied. Colon cancer cases $(n=176)$ admitted to Xiangya Hospital Central South University were selected into the study. They were divided into group A $(n=92)$ and group B $(n=84)$. In group A, patients underwent surgery anesthesia with dexmedetomidine combined with sufentanil. In group B, patients underwent surgery anesthesia only with sufentanil. The anesthesia induced intubation, operation time and incidence of postoperative adverse reaction of patients were compared between the two groups. Heart rate (HR), systolic blood pressure (SBP) and diastolic blood pressure (DBP) were observed and recorded before induction, before intubation and after intubation. Blood coagulation analyzer was used to detect four items of coagulation before and after operation. FACSCalibur flow cytometry was used to detect T lymphocyte subsets in peripheral blood of patients in the two groups. The pain scores (VAS) of patients in the two groups were measured and recorded after surgery at 4, 24 and $48 \mathrm{~h}$. There was a difference in anesthesia induced intubation and operation time of patients in both groups $(\mathrm{P}<0.05)$. There were differences in $\mathrm{HR}, \mathrm{SBP}$ and DBP of patients in both groups after intubation $(\mathrm{P}<0.05)$, in postoperative coagulation function $(\mathrm{P}<0.05)$, and in postoperative immune function of patients in both groups $(\mathrm{P}<0.05)$. The VAS scores of patients in both groups were different at different time-points after operation $(\mathrm{P}<0.05)$. There were differences in postoperative adverse reactions of patients in both groups $(\mathrm{P}<0.05)$. Dexmedetomidine combined with sufentanil is a viable anesthetic regimen for colon cancer
\end{abstract}

Correspondence to: Dr Yinglan Li, Xiangya Nursing School, Central South University, 172 Tongzipo Road, Changsha, Hunan 410013, P.R. China

E-mail: n456sz@163.com; yuyan0202@sina.com

Key words: dexmedetomidine combined with sufentanil, colon cancer resection, coagulation function, immune function resection. The coagulation function and immune function have certain improvement effect for patients.

\section{Introduction}

Colon cancer is the third most common cancer in men and the second most common cancer in women (1). It is a heterogeneous disease (2). The annual incidence rate is approximately 1.2 million and more than 600 patients die each year from the colon cancer (3). Surgical resection is an early method for the clinical treatment of colon cancer. The surgical wound area is large and the patient's postoperative pain is obvious. So the anesthetic management and postoperative analgesia during surgery are important factors for patients to recover quickly after surgery.

Dexmedetomidine is a selective adrenergic agonist that has less effect on respiratory function, has anti-anxiety, antisympathetic nerve and analgesic and sedative properties (4). It is an important option for short-term or long-term sedation in intensive care units (5). Previous studies have shown that dexmedetomidine has good analgesic sedative effect, and also significantly reduces the dose of anesthetic drugs required, reduces the duration of coma and shorten duration of mechanical ventilation (6). Sufentanil is an effective analgesic that rapidly crosses the blood-brain barrier and selectively activates central $\mu$-opioid receptors (7), with a very high therapeutic index in clinical studies. There is no active metabolite, but there is a high degree of lipophilic property (8). Studies have shown that sufentanil is commonly used in intravenous and intrathecal routes to treat acute pain and can also be used for postoperative analgesia $(9,10)$. In a study on laryngectomy by Qin et al (11), dexmedetomidine combined with sufentanil improved postoperative sleep quality, had good analgesic effect and reduced the number of coughs in patients after operation.

At present, there is scarce research on dexmedetomidine combined with sufentanil in colon cancer resection and on the immune function and coagulation function of patients. This study provides more references for the treatment of patients with colon cancer resection by observing the application and anesthetic effect of dexmedetomidine combined with sufentanil in colon cancer resection. 


\section{Materials and methods}

Baseline data. Cancer patients ( $\mathrm{n}=176)$ admitted to Xiangya Hospital of Central South University, were selected for study. They were divided into group A (92 cases) and group B (84 cases). There were 42 males and 50 females in group A, aged $29-66$ years. The average age was $52.51 \pm 6.11$ years. TNM stage was 48 cases in I+II stage and 44 cases in stage III. There were 47 males and 37 females in group B, aged 27-64 years. The average age was $53.13 \pm 6.05$ years. TNM staging was 43 cases in stages I+II and 41 cases in stage III. The study was approved by the Ethics Committee of Xiangya Hospital Central South University (Changsha, China). The patients or their guardians sign a full informed consent.

Inclusion and exclusion criteria. Inclusion criteria: In line with the National Comprehensive Cancer Network (NCCN) oncology clinical practice guidelines (12); CT, color doppler ultrasound, MRI and other tests to exclude distant metastases, TNM staging criteria for stage I to III; no previous treatment or radiation therapy, and this is the first diagnosis; no major organ dysfunction, with detailed clinical and pathological data. Exclusion criteria: Patients who were unwilling to participate in this study; patients with other malignant tumors, those who did not cooperate with follow-up and who were lost to follow-up; patients with blood system diseases, comorbid with serious complications and immune system diseases; patients with severe mental illness that led to poor treatment compliance.

Operative methods. In both groups, patients underwent general anesthesia intratracheal intubation. In the two groups, patients routinely fasted before surgery, but did not receive preoperative medication. After entering the operating room, venous transfusion was opened routinely to closely monitor non-invasive arterial blood pressure, blood oxygen saturation, end tidal carbon dioxide tension, bispectral index and electrocardiogram. Then patients received sufentanil (Yichang Humanwell Pharmaceutical Co., Ltd.; item no. H20054256) of $0.5 \mu \mathrm{g} / \mathrm{kg}$, etomidate (Shanghai Shifeng Biotechnology Co., Ltd.; item no. EB03700) of $0.3 \mathrm{mg} / \mathrm{kg}$ and atracurium (Jiangsu Hengrui Pharmaceutical Co., Ltd.; item no. H20060869) of $0.15 \mathrm{mg} / \mathrm{kg}$. After successful anesthesia induction, an appropriate laryngeal mask was placed after the patient's muscles were relaxed and they were unconscious. Then the anesthesia was applied. The tidal volume was $8-10 \mathrm{ml} / \mathrm{kg}$. The respiratory rate was adjusted to 12 times/min. During operation, micro-pump continued to inject remifentanil (Yichang Humanwell Pharmaceutical Co., Ltd.; item no. H20030197) of 5-6 $\mu \mathrm{g} /(\mathrm{mg} \cdot \mathrm{h})$ and propofol (Sichuan Guorui Pharmaceutical Co., Ltd.; item no. $\mathrm{H} 20030115$ ) of $3-6 \mathrm{mg} / \mathrm{kg}$ intravenous pumping. Atracurium of $0.25-0.5 \mathrm{mg} / \mathrm{kg}$ was added to maintain anesthesia. After completion of the operation, the tube was extubated after the patient regained spontaneous breathing, cough and swallowing reflex. During analgesia, patients received $200 \mu \mathrm{g}$ of dexmedetomidine, sufentanil of $2.0 \mu \mathrm{g} / \mathrm{kg}$ and ramosetron hydrochloride of $0.3 \mathrm{mg}$ (Shanghai Yuanye Biotechnology Co., Ltd.; item no. S61106) for analgesia in group A. Patients were given analgesia with sufentanil of
$2.0 \mu \mathrm{g} / \mathrm{kg}$ and ramosetron hydrochloride of $0.3 \mathrm{mg}$ in group B. In the two groups, analgesic drugs were diluted in normal saline and to a dose of $100 \mathrm{ml}$.

Observation indexes. The time to effect of anesthetics, operation time, awakening time, extubation time and recovery time of patients in the two groups were recorded. Before induction, before and after intubation, the MAP, CVP, HR levels and the incidence of postoperative adverse reactions were measured and recorded in patients of the two groups.

Five milliliters of venous blood was taken before anesthesia induction and 30 min after surgery for 1 day. Blood coagulation analyzer HF-6000 (Hunan Hukang Centrifuge Co., Ltd.; item no. HF-6000) was used to detect four items of coagulation (PT, APTT, TT, FIB).

Five milliliters of venous blood was taken before anesthesia induction for $30 \mathrm{~min}$ and after surgery for 1 day. FACSCalibur flow cytometry (BD Biosciences) was used to detect $\mathrm{T}$ lymphocyte subsets in peripheral blood. Anticoagulated whole blood of $100 \mu 1$ was placed in a TruCOUNT tube. Twenty microliters each of CD3-FITC, CD4-PE and CD8-PE (BD Biosciences) antibody was added, mixed and allowed to stand at room temperature for $15 \mathrm{~min}$. Hemolysin of $370 \mu \mathrm{l}$ was added (BD Biosciences), mixed and allowed to stand at room temperature for 15 min. Samples were tested on a flow cytometer and the peripheral blood $\mathrm{CD}^{+}, \mathrm{CD}^{+}, \mathrm{CD}^{+}$and $\mathrm{CD} 4^{+} / \mathrm{CD} 8^{+}$ values were read.

The pain scores of patients in the two groups were measured and recorded after operation at 4, 24 and $48 \mathrm{~h}$. The visual analogue scale (VAS) was used. The scoring standard: the score was recorded by using a slidable swimming ruler with a length of $10 \mathrm{~cm}$. The scale was: 0 , painless and 10 points aggravated by pain.

Statistical analysis. The analysis was performed by using SPSS 21.0 statistical software (Easybio). Enumeration data were expressed as cases/percentage [n(\%)] within groups. Chi-square test was used to compare the enumeration data between groups. In Chi-square test, when the theoretical frequency was less than 5 , continuity correction Chi-square test was adopted. Measurement data were expressed as mean number \pm standard deviation (mean $\pm \mathrm{SD}$ ). The t-test of independent samples was used to compare the measurement data between groups. Paired t-test was used for sequential comparisons within the group. Multiple time-points were observed and compared by using repetitive measurement and analysis of variance. The Bonferroni method was used for pairwise comparison between different time-points in the group. The difference was statistically significant at $\mathrm{P}<0.05$.

\section{Results}

Baseline data. There were no significant differences in patients regarding sex, age, body mass index, place of residence, nation, educational background, smoking history, drinking history, movement history, diabetes history, obesity status, TNM stage, or other clinical baseline data between the two groups $(\mathrm{P}>0.05)$ (Table I). 
Table I. Baseline data of patients in both groups $[\mathrm{n}(\%)]($ mean $\pm \mathrm{SD})$.

\begin{tabular}{|c|c|c|c|c|}
\hline Classification & Group A $(n=92)$ & Group B $(n=84)$ & $\mathrm{t} / \chi^{2}$ value & P-value \\
\hline Sex & & & 1.864 & 0.172 \\
\hline Male & $42(45.65)$ & $47(55.95)$ & & \\
\hline Female & $50(54.35)$ & $37(44.05)$ & & \\
\hline Age/years & $52.51 \pm 6.11$ & $53.13 \pm 6.05$ & 0.676 & 0.500 \\
\hline $\mathrm{BMI}\left(\mathrm{kg} / \mathrm{m}^{2}\right)$ & $22.84 \pm 2.15$ & $22.42 \pm 1.71$ & 1.425 & 0.156 \\
\hline Place of residence & & & 2.582 & 0.108 \\
\hline City & $56(60.87)$ & $41(48.81)$ & & \\
\hline Rural & $36(39.13)$ & $43(51.19)$ & & \\
\hline Ethnicity & & & 0.001 & 0.978 \\
\hline Han & $48(52.17)$ & $44(52.38)$ & & \\
\hline Minority & $44(47.83)$ & $40(47.62)$ & & \\
\hline Educational background & & & 0.046 & 0.831 \\
\hline$\geq$ High school & $42(45.65)$ & $37(44.05)$ & & \\
\hline$<$ High school & $50(54.35)$ & 47 (55.95) & & \\
\hline Smoking history & & & 2.366 & 0.124 \\
\hline Yes & $43(46.74)$ & $49(58.33)$ & & \\
\hline No & $49(53.26)$ & 35 (41.67) & & \\
\hline Drinking history & & & 0.175 & 0.676 \\
\hline Yes & $53(57.61)$ & $51(60.71)$ & & \\
\hline No & $39(42.39)$ & $33(39.29)$ & & \\
\hline Movement history & & & 1.547 & 0.214 \\
\hline Yes & $62(67.39)$ & $49(58.33)$ & & \\
\hline No & $30(32.61)$ & 35 (41.67) & & \\
\hline Diabetes history & & & 0.039 & 0.842 \\
\hline Yes & $49(53.26)$ & $46(54.76)$ & & \\
\hline No & $43(46.74)$ & $38(45.24)$ & & \\
\hline Obesity status & & & 0.007 & 0.934 \\
\hline Yes & $52(56.52)$ & $48(57.14)$ & & \\
\hline No & $40(43.48)$ & $36(42.86)$ & & \\
\hline TNM stage & & & 0.017 & 0.896 \\
\hline Stage I+II & $48(52.17)$ & $43(51.19)$ & & \\
\hline Stage III & $44(47.83)$ & $41(48.81)$ & & \\
\hline
\end{tabular}

Comparison of anesthesia induced intubation time of patients in the two groups. There was no significant difference in the time of anesthesia taking effect of patients in the two groups $(\mathrm{P}>0.05)$. The awakening time, extubation time and recovery time of group A were lower than those of group B $(\mathrm{P}<0.05)$ (Table II).

Comparison of HR, SBP and DBP in each period of operation of patients in the two groups. The expression of HR, SBP and DBP in each time period in patients of both groups were statistically significant $(\mathrm{P}<0.05)$. There was no significant difference in HR, SBP and DBP of patients in the two groups before induction ( $\mathrm{P}>0.05)$. Before and after intubation, $\mathrm{HR}$, SBP and DBP of patients in the two groups were lower than before induction $(\mathrm{P}<0.05)$. HR, SBP and DBP before intubation were significantly lower than those after intubation $(\mathrm{P}>0.05)$. Moreover, HR, SBP and DBP in group A before and after intubation were significantly lower than those in group B $(\mathrm{P}<0.05)$ (Fig. 1).

Comparison of preoperative and postoperative coagulation functions of patients in two groups. There was no difference in the expression levels of PT, APTT, TT and FIB in coagulation function of patients in two groups before operation (P>0.05), but the expression levels of coagulation function PT, APTT, TT and FIB in group A after operation were lower than that in group $\mathrm{B}(\mathrm{P}<0.05)$ (Table III).

Comparison of immune function of patients in the two groups before and after surgery. There were no significant differences in the expression of $\mathrm{CD}^{+}, \mathrm{CD}^{+}, \mathrm{CD}^{+}, \mathrm{CD}^{+} / \mathrm{CD}^{+}$of patients in the two groups before surgery $(\mathrm{P}>0.05)$, but the expression of $\mathrm{CD}^{+}, \mathrm{CD}^{+}, \mathrm{CD}^{+}, \mathrm{CD}^{+} / \mathrm{CD}^{+}$in group A after surgery was higher than that in group $\mathrm{B}(\mathrm{P}<0.05)$ (Table IV). 
Table II. Comparison of anesthesia induced intubation time of patients in the two groups (mean $\pm \mathrm{SD}, \mathrm{min}$ ).

\begin{tabular}{lcccc}
\hline Items & Group A $(\mathrm{n}=92)$ & Group B $(\mathrm{n}=84)$ & $\mathrm{t}$ value & P-value \\
\hline Time of anesthesia taking effect & $4.78 \pm 1.04$ & $5.02 \pm 1.13$ & 1.467 & 0.144 \\
Awakening time & $13.48 \pm 2.53$ & $14.89 \pm 2.96$ & 3.406 & 0.001 \\
Extubation time & $11.26 \pm 3.12$ & $12.56 \pm 3.45$ & 2.625 & 0.009 \\
Recovery time & $10.46 \pm 2.78$ & $11.56 \pm 2.83$ & 2.600 & 0.010
\end{tabular}

Table III. Comparison of preoperative and postoperative coagulation functions of patients in the two groups (mean \pm SD).

\begin{tabular}{|c|c|c|c|c|c|c|c|c|}
\hline \multirow[b]{2}{*}{ Grouping } & \multicolumn{2}{|c|}{ PT (sec) } & \multicolumn{2}{|c|}{ APTT (sec) } & \multicolumn{2}{|c|}{ TT (sec) } & \multicolumn{2}{|c|}{ FIB (g/l) } \\
\hline & $\begin{array}{l}\text { Before } \\
\text { surgery }\end{array}$ & $\begin{array}{c}\text { After } \\
\text { surgery }\end{array}$ & $\begin{array}{l}\text { Before } \\
\text { surgery }\end{array}$ & $\begin{array}{c}\text { After } \\
\text { surgery }\end{array}$ & $\begin{array}{l}\text { Before } \\
\text { surgery }\end{array}$ & $\begin{array}{c}\text { After } \\
\text { surgery }\end{array}$ & $\begin{array}{l}\text { Before } \\
\text { surgery }\end{array}$ & $\begin{array}{l}\text { After } \\
\text { surgery }\end{array}$ \\
\hline Group A (n=92) & $15.8 \pm 4.6$ & $11.3 \pm 4.3$ & $35.9 \pm 12.4$ & $26.5 \pm 11.9$ & $15.9 \pm 5.2$ & $12.3 \pm 5.1$ & $4.2 \pm 0.2$ & $2.3 \pm 0.2$ \\
\hline Group B $(n=84)$ & $15.9 \pm 4.5$ & $13.2 \pm 4.2$ & $36.2 \pm 12.1$ & $31.3 \pm 12.0$ & $16.7 \pm 5.3$ & $14.2 \pm 5.0$ & $4.3 \pm 0.6$ & $3.1 \pm 0.3$ \\
\hline $\mathrm{t}$ value & 0.146 & 2.961 & 0.162 & 2.662 & 1.010 & 2.492 & 1.510 & 20.980 \\
\hline P-value & 0.884 & 0.004 & 0.871 & 0.009 & 0.314 & 0.014 & 0.133 & $<0.001$ \\
\hline
\end{tabular}
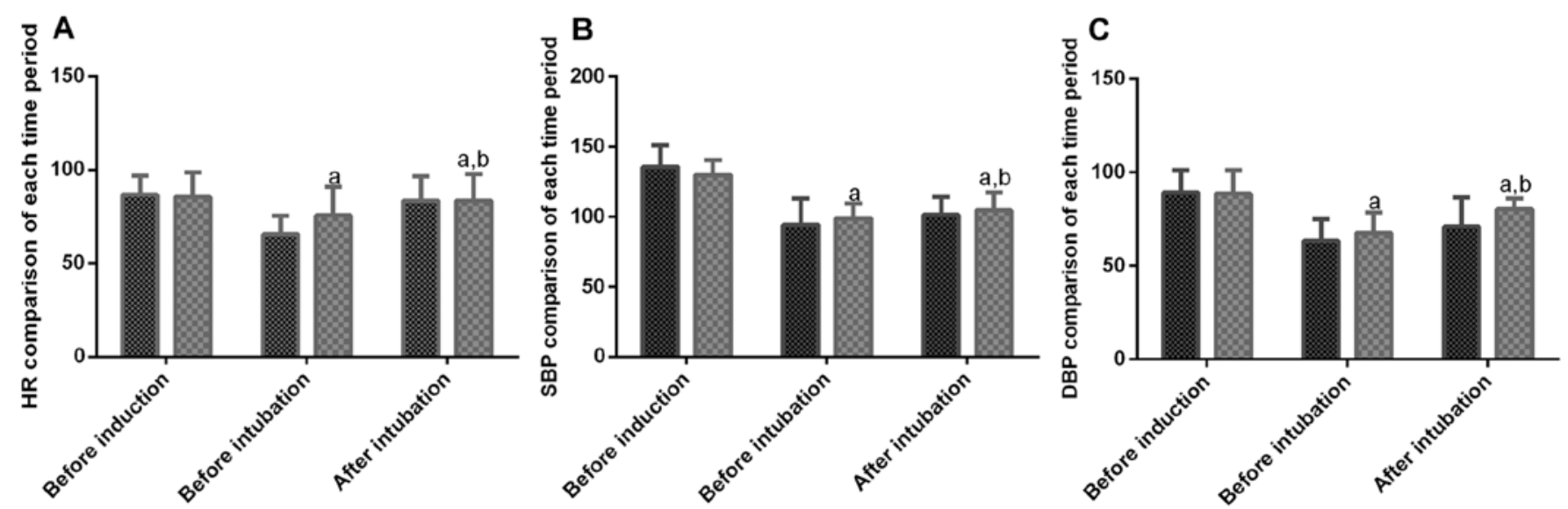

Figure 1. Comparison of (A) HR, (B) SBP and (C) DBP in each period of operation in the two groups. The expression of HR, SBP and DBP in each time period in patients of both groups were statistically significant $(\mathrm{P}<0.05)$. There was no significant difference in $\mathrm{HR}$, SBP and DBP of patients in the two groups before induction $(\mathrm{P}<0.05)$. Before and after intubation, HR, SBP and DBP of patients in the two groups were lower than before induction $(\mathrm{P}<0.05)$. HR, SBP and DBP before intubation were significantly lower than those after intubation $(\mathrm{P}<0.05)$. Moreover, HR, SBP and DBP in group A before and after intubation were significantly lower than those in group $\mathrm{B}(\mathrm{P}<0.05)$. ${ }^{\mathrm{a}} \mathrm{P}<0.05$ compared with group $\mathrm{B}$ before induction; ${ }^{\text {b }} \mathrm{P}<0.05$ compared with group $\mathrm{B}$ before intubation.

Comparison of VAS scores of patients in the two groups after operation. The VSA scores of patients in the two groups were significantly decreased with time, with statistical significance $(\mathrm{P}<0.05)$. The VAS scores of the patients in group A were lower than those in group B after operation at 4,24 and $48 \mathrm{~h}$ $(\mathrm{P}<0.05)($ Table V).

Incidence of adverse reactions of patients in the two groups after operation. In group A, there was 1 case with shivering (1.09\%), 2 cases with nausea, vomiting and headache $(2.17 \%)$ and 1 case with respiratory depression (1.09\%). The incidence of total adverse reactions was $4.35 \%$. In group B, there were 2 cases with shivering $(2.38 \%), 4$ cases with nausea and vomiting $(4.76 \%), 5$ cases with headache $(5.95 \%), 5$ cases with respiratory depression $(5.95 \%)$. The incidence of total adverse reactions was $19.05 \%$. The total adverse reaction rate of patients in group A was significantly lower than that of patients in group $\mathrm{B}(\mathrm{P}<0.05)$ (Table VI).

\section{Discussion}

Colon cancer is common (13). Most of the pathogenesis is slow and occult and early symptoms are not obvious (14). Colon cancer is clinically treated with surgical resection (15), but postoperative pain is a common complication after surgery. It is of great significance to improve the therapeutic effect of colon cancer surgery and patient's postoperative recovery by applying reasonable anesthesia in the surgical treatment (16). 
Table IV. Comparison of immune function of patients in the two groups before and after surgery (mean \pm SD).

\begin{tabular}{|c|c|c|c|c|c|c|c|c|}
\hline \multirow[b]{2}{*}{ Grouping } & \multicolumn{2}{|c|}{$\mathrm{CD}^{+}(\%)$} & \multicolumn{2}{|c|}{$\mathrm{CD}^{+}(\%)$} & \multicolumn{2}{|c|}{$\mathrm{CD}^{+}(\%)$} & \multicolumn{2}{|c|}{$\mathrm{CD}^{+} / \mathrm{CD}^{+}{ }^{+}$} \\
\hline & $\begin{array}{l}\text { Before } \\
\text { surgery }\end{array}$ & $\begin{array}{c}\text { After } \\
\text { surgery }\end{array}$ & $\begin{array}{l}\text { Before } \\
\text { surgery }\end{array}$ & $\begin{array}{c}\text { After } \\
\text { surgery }\end{array}$ & $\begin{array}{l}\text { Before } \\
\text { surgery }\end{array}$ & $\begin{array}{c}\text { After } \\
\text { surgery }\end{array}$ & $\begin{array}{l}\text { Before } \\
\text { surgery }\end{array}$ & $\begin{array}{c}\text { After } \\
\text { surgery }\end{array}$ \\
\hline Group A $(n=92)$ & $55.88 \pm 9.29$ & $45.74 \pm 7.47$ & $33.49 \pm 5.71$ & $24.11 \pm 5.89$ & $21.44 \pm 4.11$ & $20.99 \pm 3.71$ & $1.57 \pm 0.24$ & $1.19 \pm 0.26$ \\
\hline Group B $(n=84)$ & $54.91 \pm 8.69$ & $48.62 \pm 6.62$ & $32.46 \pm 5.57$ & $22.33 \pm 4.10$ & $21.05 \pm 3.72$ & $19.78 \pm 3.85$ & $1.56 \pm 0.20$ & $1.11 \pm 0.27$ \\
\hline t value & 0.714 & 2.697 & 1.209 & 2.306 & 0.658 & 2.123 & 0.299 & 2.002 \\
\hline $\mathrm{P}$-value & 0.477 & 0.008 & 0.228 & 0.022 & 0.512 & 0.035 & 0.766 & 0.046 \\
\hline
\end{tabular}

Table V. Comparison of VAS scores in each period in the two groups after operation (mean $\pm \mathrm{SD}$ ).

\begin{tabular}{lcccc}
\hline Time & Group A (n=92) & Group B (n=84) & t value & P-value \\
\hline After operation for 4 h & $4.27 \pm 0.52$ & $6.32 \pm 1.12$ & 15.790 & $<0.001$ \\
After operation for 24 h & $3.45 \pm 0.44$ & $3.87 \pm 0.62$ & 5.217 & $<0.001$ \\
After operation for 48 h & $2.78 \pm 0.35$ & $3.12 \pm 0.41$ & 5.932 & $<0.001$ \\
F-value & 262.100 & 390.600 & - & - \\
P-value & $<0.001$ & $<0.001$ & - & - \\
\hline
\end{tabular}

Table VI. Incidence of total adverse reactions of patients in the two groups after operation [n(\%)].

\begin{tabular}{lcccr}
\hline Category & Group A (n=92) & Group B (n=84) & $\chi^{2}$ value & P-value \\
\hline Shivering & $1(1.09)$ & $2(2.38)$ & 0.439 & 0.508 \\
Nausea and vomiting & $0(0.00)$ & $4(4.76)$ & 4.483 & 0.034 \\
Headache & $2(2.17)$ & $5(5.95)$ & 1.641 & 0.200 \\
Respiratory depression & $1(1.09)$ & $5(5.95)$ & 3.157 & 0.076 \\
Incidence of total adverse reactions & $4(4.35)$ & $16(19.05)$ & 9.420 & 0.002 \\
\hline
\end{tabular}

Dexmedetomidine reduces the sympathetic nerves of the heart and surrounding vasculature or enhances the tension of parasympathetic nerve to alter hemodynamics (17). Previous studies have shown that (18) dexmedetomidine can also improve postoperative cellular immune function of patients with malignant tumors. Sufentanil is a widely used analgesic that improves the analgesic effect with a longer duration and a lighter respiratory inhibition (19). It also has a strong opioid receptor activation effect. Its obvious analgesic effect and the possibility of cardiovascular events are low (20). In this study, there was no significant difference in the time of anesthesia taking effect of patients in group A and group B. However, the awakening time, extubation time and recovery time after anesthesia in group A was lower than group B. MAP and CVP were significantly decreased before intubation and HR was significantly slowed. However, after intubation, it recovered to before induction level and group A was lower than group B, indicating that dexmedetomidine combined with sufentanil can provide more stable hemodynamics for patients with colon cancer resection. The VAS scores of patients in group A were significantly lower than those of patients in group B after surgery for 4, 24 and $48 \mathrm{~h}$, indicating that the awakening time language statement and awakening time of dexmedetomidine combined with sufentanil were faster in colon cancer resection, and the postoperative analgesic effect was better. In the study of Dong et al (21), the use of dexmedetomidine and sufentanil in thoracotomy was shown to successfully treat severe pain of patients after thoracotomy and to maintain good hemodynamic stability, similarly to this study. We observed the adverse reactions of patients after surgery and the results showed that the incidence of total adverse reactions in group A was significantly lower than that in group B, indicating that dexmedetomidine and sufentanil were safer.

Blood coagulation of perioperative patients is affected by various factors such as the size of the operation, blood loss, anesthesia and blood transfusion (22). In the study of Chen et al (23), the combination of anesthesia and dexmedetomidine also improved the postoperative coagulation status of patients. The results of the present study showed that the expression levels of coagulation function PT, APTT, TT and FIB in group A were lower than those in group B, indicating that dexmedetomidine combined with sufentanil can effectively improve postoperative coagulation function in patients with colon cancer resection. Dexmedetomidine inhibits sympathetic nerve activity, while sufentanil combined with dexmedetomidine can inhibit sympathetic nerve activity and 
play the role of inhibiting stress response, thereby preventing blood from becoming hypercoagulated and accelerating blood flow.

Changes of $\mathrm{T}$ lymphocyte subsets can assess the immune function of the body. $\mathrm{CD}^{+}, \mathrm{CD}^{+}$and $\mathrm{CD} 8^{+} \mathrm{T}$ cells can be classified according to their different functions and surface markers. The changes in the ratio of the three are important markers reflecting the immune dysfunction of the body (24). The results of this study showed that the ratio of $\mathrm{CD}^{+}$, $\mathrm{CD}^{+}, \mathrm{CD}^{+}$and $\mathrm{CD}^{+} / \mathrm{CD}^{+}$in peripheral blood of group $\mathrm{A}$ and group $\mathrm{B}$ after operation was significantly lower than that before operation. The ratio of $\mathrm{CD}^{+}, \mathrm{CD}^{+}, \mathrm{CD}^{+}$and $\mathrm{CD}^{+} / \mathrm{CD}^{+}$in group A was significantly higher than that in group $\mathrm{B}$, indicating that anesthesia may have an impact on the immune function of patients with colon cancer resection, while dexmedetomidine combined with sufentanil have less effect on the immune function of patients. In the study of Yang et al (25), dexmedetomidine, sufentanil and other anesthesia were applied to patients receiving radical mastectomy, which could effectively improve the immune function of patients. This indicated that dexmedetomidine and sufentanil can improve the immune function of patients.

This study confirmed that dexmedetomidine combined with sufentanil is a viable anesthesia program in colon cancer resection. However, further study is necessary to extend the study time and add follow-up to further confirm the results.

In conclusion, dexmedetomidine combined with sufentanil is a viable anesthetic regimen for colon cancer resection, which can maintain good hemodynamic stability, effectively relieve postoperative pain of patients and has fewer postoperative complications. The coagulation function and immune function also have a certain improvement effect in patients.

\section{Acknowledgements}

Not applicable.

\section{Funding}

No funding was received.

\section{Availability of data and materials}

The datasets used and/or analyzed during the present study are available from the corresponding author on reasonable request.

\section{Authors' contributions}

$\mathrm{LZ}$ wrote the manuscript, interpreted and analyzed the patient data. YL designed the study, performed the experiment, and was responsible for the analysis and discussion of the data. Both authors read and approved the final manuscript.

\section{Ethics approval and consent to participate}

The study was approved by the Ethics Committee of Xiangya Hospital Central South University (Changsha, China). Patients who participated in this research had complete clinical data. Signed informed consents were obtained from the patients and/or the guardians.

\section{Patient consent for publication}

Not applicable.

\section{Competing interests}

The authors declare that they have no competing interests.

\section{References}

1. Marisa L, de Reyniès A, Duval A, Selves J, Gaub MP, Vescovo L, Etienne-Grimaldi MC, Schiappa R, Guenot D, Ayadi M, et al: Gene expression classification of colon cancer into molecular subtypes: Characterization, validation, and prognostic value. PLoS Med 10: e1001453, 2013.

2. Sinicrope FA, Shi Q, Smyrk TC, Thibodeau SN, Dienstmann R, Guinney J, Bot BM, Tejpar S, Delorenzi M, Goldberg RM, et al: Molecular markers identify subtypes of stage III colon cancer associated with patient outcomes. Gastroenterology 148: 88-99, 2015.

3. Warschkow R, Sulz MC, Marti L, Tarantino I, Schmied BM, Cerny $\mathrm{T}$ and Güller U: Better survival in right-sided versus left-sided stage I-III colon cancer patients. BMC Cancer 16: 554, 2016.

4. Weerink MA, Struys MM, Hannivoort LN, Barends CR, Absalom AR and Colin P: Clinical pharmacokinetics and pharmacodynamics of dexmedetomidine. Clin Pharmacokinet 56: 893-913, 2017.

5. Keating GM: Dexmedetomidine: A review of its use for sedation in the intensive care setting. Drugs 75: 1119-1130, 2015.

6. Grant MJ, Schneider JB, Asaro LA, Dodson BL, Hall BA, Simone SL, Cowl AS, Munkwitz MM, Wypij D and Curley MA; Randomized Evaluation of Sedation Titration for Respiratory Failure Study Investigators: Dexmedetomidine use in critically ill children with acute respiratory failure. Pediatr Crit Care Med 17: 1131-1141, 2016.

7. van de DonkT, Ward S,Langford Rand Dahan A: Pharmacokinetics and pharmacodynamics of sublingual sufentanil for postoperative pain management. Anaesthesia 73: 231-237, 2018.

8. Willsie SK, Evashenk MA, Hamel LG, Hwang SS, Chiang YK and Palmer PP: Pharmacokinetic properties of single- and repeated-dose sufentanil sublingual tablets in healthy volunteers. Clin Ther 37: 145-155, 2015.

9. Porela-Tiihonen S, Kokki M and Kokki H: Sufentanil sublingual formulation for the treatment of acute, moderate to severe postoperative pain in adult patients. Expert Rev Neurother 17: 101-111, 2017.

10. Ohnesorge H, Alpes A, Baron R and Gierthmühlen J: Influence of intraoperative remifentanil and sufentanil on sensory perception: A randomized trial. Curr Med Res Opin 32: 1797-1805, 2016.

11. Qin M, Chen K, Liu T and Shen X: Dexmedetomidine in combination with sufentanil for postoperative analgesia after partial laryngectomy. BMC Anesthesiol 17: 66, 2017.

12. Benson AB III, Venook AP, Cederquist L, Chan E, Chen YJ, Cooper HS, Deming D, Engstrom PF, Enzinger PC, Fichera A, et al: Colon cancer, version 1.2017, NCCN clinical practice guidelines in oncology. J Natl Compr Canc Netw 15: 370-398, 2017.

13. Schweiger MR, Hussong M, Röhr C and Lehrach H: Genomics and epigenomics of colorectal cancer. Wiley Interdiscip Rev Syst Biol Med 5: 205-219, 2013.

14. Soler M, Estevez MC, Villar-Vazquez R, Casal JI and Lechuga LM: Label-free nanoplasmonic sensing of tumor-associate autoantibodies for early diagnosis of colorectal cancer. Anal Chim Acta 930: 31-38, 2016.

15. Arnarson Ö, Butt-Tuna S and Syk I: Postoperative complications following colonic resection for cancer are associated with impaired long-term survival. Colorectal Dis 21: 805-815, 2019.

16. Li L, Jin J, Min S, Liu D and Liu L: Compliance with the enhanced recovery after surgery protocol and prognosis after colorectal cancer surgery: A prospective cohort study. Oncotarget 8: 53531-53541, 2017.

17. Devcic A, Schmeling WT, Kampine JP and Warltier DC: Oral dexmedetomidine preserves baroreceptor function and decreases anesthetic requirements of halothane-anesthetized dogs. Anesthesiology 81: 419-430, 1994. 
18. Chen J, Fang JI, Lei Z, Zhang Z, Yiheshan A and Zhang B: Effect of dexmedetomidine on postoperative cellular immune function in patients with malignant tumor: A meta-analysis. Chin J Anesthesiol 4: 454-457, 2018 (In Chinese).

19. Feng M, Chen X, Liu T, Zhang C, Wan L and Yao W: Dexmedetomidine and sufentanil combination versus sufentanil alone for postoperative intravenous patient-controlled analgesia: A systematic review and meta-analysis of randomized controlled trials. BMC Anesthesiol 19: 81, 2019.

20. Ma XX, Luo F and Lan R: Effects of dexmedetomidine combined with sufentanil on $\mathrm{P} 2 \mathrm{X} 7$ receptor expression in peripheral blood mononuclear cells in patients with burn pain. Acta Microscopica 28: 2019.

21. Dong CS, Zhang J, Lu Q, Sun P, Yu JM, Wu C and Sun H: Effect of dexmedetomidine combined with sufentanil for post-thoracotomy intravenous analgesia:a randomized, controlled clinical study. BMC Anesthesiol 17: 33, 2017.
22. Liuboshevskiǔ PA, Artamonova NI and Ovechkin AM: Haemostasis disturbances as the component of the surgical stress-response and possibilities of their correction. Anesteziol Reanimatol 3: 44-48, 2012 (In Russian).

23. Chen Z, Shao D, Mao Z, Shi L, Zheng Y and Zhang D: Effect of dexmedetomidine on blood coagulation function following radical gastrectomy. J Clin Anesthesiol 33: 1086-1090, 2017.

24. Sun HZ, Song YL and Wang XY: Effects of different anesthetic methods on cellular immune and neuroendocrine functions in patients with hepatocellular carcinoma before and after surgery. J Clin Lab Anal 30: 1175-1182, 2016.

25. Yang XH, Bai Q, Lv MM, Fu HG, Dong TL and Zhou Z: Effect of dexmedetomidine on immune function of patients undergoing radical mastectomy: a double blind and placebo control study. Eur Rev Med Pharmacol Sci 21: 1112-1116, 2017.

(c) () $(9$ This work is licensed under a Creative Commons cc) Attribution-NonCommercial-NoDerivatives 4.0 International (CC BY-NC-ND 4.0) License. 